\title{
Thirteen cystic fibrosis patients, 12 compound heterozygous and one homozygous for the missense mutation G85E: a pancreatic sufficiency/insufficiency mutation with variable clinical presentation
}

Carlos Vazquez, Guillermo Antiñolo, Teresa Casals, Javier Dapena, Javier Elorz, Jose L Seculi, Josep Sirvent, Rodrigo Cabanas, Concepción Soler, Xavier Estivill

Cystic Fibrosis Unit, Hospital Infantil de Cruces, Plaza de Cruces sn, PO Box 48903, Barakaldo, Vizcaya, Pais Vasco,

Spain

J Elorz

Medical Genetics Unit, Hospital Virgen del Rocio, Sevilla, Spain G Antiñolo

Cystic Fibrosis Unit, Hospital Virgen del Rocio, Sevilla, Spain

J Dapena

Molecular Genetics Department, Cancer

Research Institute,

Hospital Duran i

Reynals, Barcelona,

Spain

T Casals

$\mathrm{X}$ Estivill

Cystic Fibrosis Unit, Hospital San Juan de Dios, Barcelona, Spain J L Seculi

Cystic Fibrosis Unit, Hospital

Materno-Infantil, La

Coruña, Spain

J Sirvent

Servicio de Pediatria, Hospital Xeral de Galicia, Santiago,

Spain

R Cabanas

Servicio de Pediatria, Hospital Xeral de Vigo, Spain

C Soler

Correspondence to:

Dr Vazquez.

Received 4 December 1995 Revised version accepted fo publication 28 May 1996

\begin{abstract}
To study the severity of mutation G85E, located in the first membrane spanning domain of the CFTR gene, we studied the clinical features of 13 Spanish patients with cystic fibrosis (CF) carrying this mutation. G85E accounts for about $1 \%$ of Spanish CF alleles. One patient was homozygous G85E/G85E and the rest were compound heterozygotes for G85E and other mutations ( $\Delta$ F508 nine patients, $\Delta I 507$ two patients, and 712-1G $>$ T one patient). The characteristics of the pooled G85E/any mutation group were compared with those of $30 \Delta$ F508 homozygotes. Mean age at diagnosis and percentage of ideal height for age were higher in the G85E/any mutation group (4.2 (SD 4.7) $v 2.4$ (SD 2.3), $\mathrm{p}<0.05$, and 102.8 (SD 4.7) $v$ 97.8 (SD $4.1), p<0.01)$ ), both probably related to the greater prevalence of pancreatic sufficiency $(70 \% v 0 \%, p<0.01)$. The G85E homozygote was pancreatic sufficient. Sweat sodium levels were slightly higher, and salt loss related problems more frequent, in the G85E/any group. Two of the G85E patients died of respiratory failure aged 6 and 14 years. Striking discordance in the phenotype was observed in two pairs of sibs, one of them dizygotic twins, suggesting that factors, genetic and environmental, other than CFTR genotype are important in determining CF phenotype. ( $(\mathcal{M}$ Med Genet 1996;33:820-822)
\end{abstract}

Key words: cystic fibrosis; CFTR mutations; phenotype; G85E mutation.

Cystic fibrosis (CF) is the commonest life threatening autosomal recessive disorder in white populations, with an incidence of $1 / 2000$ to $1 / 4000 .^{1}$ The gene responsible for the disease encodes the CF transmembrane conductance regulator protein (CFTR). ${ }^{23}$ Over 500 different mutations have been identified. The frequency of most of these is very low, and varies considerably among different populations. $^{4}$

Clinical manifestations of CF include pancreatic insufficiency (PI), chronic pulmonary disease, raised sweat chloride and sodium levels, and bilateral absence of the vas deferens. A number of genotype-phenotype correlations have been studied and have shown that while the link between genotype and pancreatic function is usually strong, correlations with other characteristics are far more elusive. ${ }^{5}$ Some of the features of classical CF may sometimes be lacking leading to "mild" or "atypical" forms ${ }^{6-17}$ Many mutations associated with such phenotypes are missense substitutions in the membrane spanning domains (MSD) of the CFTR. ${ }^{79-15}$ Some of these mutant proteins are normally processed and located in the apical membrane, and lead to cAMP regulated $\mathrm{Cl}$ currents, ${ }^{15}$ although smaller than normal (class IV mutations ${ }^{6}$ ). Conversely missense mutations located in the nucleotide binding folds are usually severe. ${ }^{18}$ Other mutations associated with mild CF are some splicing mutations in which low levels of normal transcripts are produced. ${ }^{16}{ }^{17}$ We present here the clinical findings in 13 Spanish CF patients carrying the missense mutation G85E, a $G$ to A change at nucleotide position 386 in exon 3, which results in a glutamic acid for glycine substitution at codon 85 in the first MSD of the CFTR. ${ }^{19}$

Clinical data of the patients were obtained from several centres. Patients 7-12 were under care at Hospital de Cruces and patients 1-6 were each at different hospitals around the country. Another hospital (Aranzazu, San Sebastian) provided the clinical data of patient 13 , an older sib of patient 8 , who died before $\mathrm{CF}$ genotyping was feasible. The clinical features of patients with a G85E/any mutation genotype were compared with those of 30 $\Delta F 508$ homozygotes under control at Hospital de Cruces. For the statistical analysis, in the case of continuous variables, means were compared by unpaired two tailed Student's $t$ and Mann-Whitney tests. Chi squared analysis was used to assess differences between groups for categorical variables. A $p$ value $<0.05$ was considered significant.

Pancreatic status was assessed by quantitative fat excretion analysis and determination of stool chymotrypsin concentrations. ${ }^{20}$ These data were not available for four patients in whom we relied on their clinical need for pancreatic enzymes. The best FEV1 over the last year was chosen as an index of pulmonary 
Table 1 Clinical features of $13 C F$ patients carrying the G85E mutation compared with $\Delta F 508$ homozygotes

\begin{tabular}{lll}
\hline & Genotype & \\
\cline { 2 - 3 } Parameter & G85E/any & $\Delta F 508 / \Delta F 508$ \\
\hline No of patients & 13 & 30 \\
Sex: female/male & $6 / 7$ & $12 / 18$ \\
Alive & 11 & 28 \\
& Mean, SD (No studied) & \\
Current age (y) & $8.4,5.4(11)$ & $9.9,4.3(28)$ \\
Age at diagnosis (y) & $4.23,4.7(13)$ & $2.4,2.3(30)^{\star}$ \\
Sweat sodium (mmol/1) & $105.1,17.0(7)$ & $94.3,14.0(23)^{\star}$ \\
Sweat chloride (mmol/1) & $107.2,4.0(5)$ & $97.5,14.0(22)$ \\
Schwachman score & $87.5,7.5(10)$ & $88.7,9.4(28)$ \\
Chrispin-Norman chest $x$ ray score & $4.5,3.1(9)$ & $4.7,5.3(27)$ \\
FEV1 (\% predicted) & $80.2,8.2(6)$ & $87.1,13(24)$ \\
FVC (\% predicted) & $85.3,7.7(6)$ & $94.8,14.6(24)$ \\
\% Ideal body weight & $101.4,14.2(10)$ & $100.7,11.2(28)$ \\
\% Ideal body height & $102.8,4.7(10)$ & $97.8,4.1(28)^{\star \star}$ \\
& $N o$ positive/No studied $(\%)$ & \\
Pancreatic insufficiency & $4 / 13(30.7)$ & $30 / 30(100)^{\star \star}$ \\
Colonisation with $P$ aeruginosa & $10 / 13(76.9)$ & $24 / 30(80)$ \\
Chronic bronchial infection with P aeruginosa & $5 / 13(38.4)$ & $10 / 30(33.3)$ \\
Meconium ileus & $0 / 13(0)$ & $2 / 30(6.7)$ \\
Liver disease & $1 / 13(7.6)$ & $2 / 30(6.7)$ \\
Dehydration and metabloic alkalosis & $4 / 13(30.7)$ & $1 / 30(3.4)^{\star}$ \\
\hline
\end{tabular}

${ }^{\star} \mathrm{p}<0.05,{ }^{\star \star} \mathrm{p}<0.01$

function. Age at which a first sputum or throat swab positive for Pseudomonas aeruginosa was obtained ("colonisation"), and presence of chronic bronchial infection (CBI) with $P$ aeruginosa, were recorded. Ideal weight for height and height for age were determined from growth charts for Spanish children. Only sweat samples collected with either the preweighted gauze Gibson and Cooke method or the Wescor Macroduct system $^{21}$ were used for comparison.

Screening by $\mathrm{DGGE}^{22}$ of 50 DNA samples with unknown mutations showed one sample with an abnormal pattern in exon 3. Direct sequencing allowed us to identify the G85E mutation. The microsatellite haplotype 1624-13 (IVS8CA-IVS17bTA-IVS17bCA) ${ }^{23}$ was used to study $\mathrm{CF}$ samples with uncharacterised mutations from $160 \mathrm{CF}$ patients. G85E was found in 13 samples.

All chromosomes with mutation G85E were associated with the same microsatellite haplotype 16-24-13. Nine patients were compound heterozygotes for $\Delta \mathrm{F} 508 / \mathrm{G} 85 \mathrm{E}$, one pair of sibs were $\mathrm{G} 85 \mathrm{E} / \Delta \mathrm{I} 507$, one was $\mathrm{G} 85 \mathrm{E} / 712-1$ $\mathrm{G}>\mathrm{T}$, and one was a G85E homozygote. Data from $\mathrm{G} 85 \mathrm{E} / \Delta \mathrm{F} 508$ and G85E/non- $\Delta \mathrm{F} 508$ patients were pooled for comparison with those from $\Delta$ F508 homozygotes.
The G85E/any mutation patients were older at diagnosis, had a higher percentage of ideal height, and a lower prevalence of PI $(30 \% v$ $100 \%, \mathrm{p}<0.01)$ compared with the $\Delta \mathrm{F} 508$ homozygotes (table 1). Sweat sodium was higher and there was a greater prevalence of dehydration-hypochloraemic metabolic alkalosis in the former. No other difference in the variables studied was found. Two patients in each group died of severe respiratory disease. Ages at death were 6 and 14 years in the G85E/any group, and 16 and 18 years in the $\Delta F 508$ homozygous group.

Table 2 shows the clinical features of the 13 patients, exhibiting a wide variability in clinical presentation. The G85E homozygote was a 17 year old girl with pancreatic sufficiency (PS), who had recurrent coughing from the age of 4 and was diagnosed at the age of 13 years. She had mild pulmonary function impairment without CBI. Two pairs of sibs (patients 8 and 13 and 11 and 12) were notable for their discordant phenotype. Patient 13 had classical CF with PI and severe respiratory disease and died of respiratory failure aged 6 . His younger sib (patient 8) had PS and remained largely free of respiratory symptoms at the age of 8 , with forced expiratory flows and chest $x$ ray within normal limits. Patients 11 and 12 were dizygotic twins. While the boy had mild pulmonary disease with normal spirometry, had PI, and showed clinical and ultrasound evidence of portal hypertension, his twin sister had PS, was free of liver disease, and had moderate pulmonary disease.

The worldwide prevalence of $\mathrm{G} 85 \mathrm{E}$ is $0.2 \%,{ }^{4}$ but higher frequencies have been reported in the US $(0.7 \%),{ }^{24}$ Italy $(1.7 \%),{ }^{25}$ and Spain (1\%) (T Casals, personal communication). This mutation causes the substitution of a negatively charged amino acid for an uncharged one within the first MSD. The molecular mechanism of the CFTR dysfunction associated with G85E has recently been found to consist of a trafficking defect (class II mutation $)^{6}$ with rapid degradation of the mutant protein before transit through the Golgi complex. ${ }^{26}$ There have been only three reports on the clinical characteristics associated with this mutation. Chalkley and Harris ${ }^{27}$ described an 11 year old boy, homozygous for G85E, with PS. Kerem et $a l^{8}$ reported five G85E homozygotes and eight compound

Table 2 Characteristics of 13 CF patients with mutation $G 85 E^{\star}$

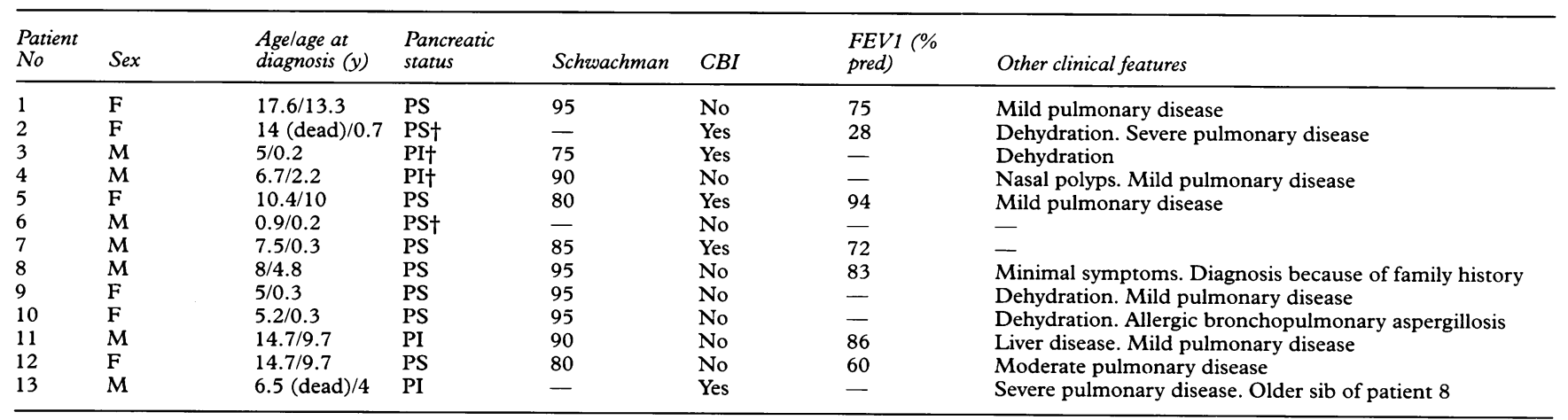

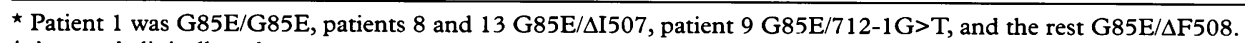

† Assessed clinically only. 
heterozygotes, only two (15.3\%) with PS. Friedman et $a l^{4}$ reported that six out of their nine patients with G85E had PS.

The data presented here suggest that G85E is predominantly associated with PS. This inconsistent association of G85E with PS, and the clinical discordance in our two pairs of sibs, suggest that genetic factors other than $\mathrm{CF}$ genotype, as well as environmental factors, are involved in the severity of the disease. These factors seem more evident when the CF mutations are mild, as has been shown for mutation

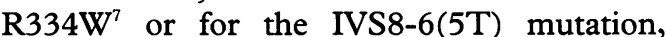
which is associated with male infertility, mild $\mathrm{CF}$, or even a normal phenotype.

In summary G85E occurred with PS in $70 \%$ of the cases. Compared with $\Delta \mathrm{F} 508$ homozygotes, patients with G85E were diagnosed later, were taller, and had a higher prevalence of dehydration, but no other difference was observed either in the severity of the pulmonary disease or in the prevalence of other CF related complications. This mutation also shows intrafamilial variability in its clinical presentation. Further experience over a longer time span is needed to clarify the comparative severity of the phenotype associated with G85E.

We are most grateful to Dr J E Olivera for referring patients 11 and 12 and Begoña Matía, RN, for her thorough laboratory and 12 and Begona work. The work of the Barcelona group is supported by the 0202), and the Institut Català de la Salut.

1 Welsh MJ, Tsui LC, Boat TF, Beaudet AL. Cystic fibrosis In: Scriver CR, Beaudet AL, Sly WS, Valle D, eds. The metabolic and molecular bases of inherited

2 Kerem B, Rommens JM, Buchanan JA, et al. Identification of the cystic fibrosis gene: genetic analysis. Science 1989;245:1073-9.

3 Riordan JR, Rommens JM, Kerem BS, et al. Identification of the cystic fibrosis gene: cloning and characterization of the complementary DNA. Science 1989;245:1066-72.

4 Cystic Fibrosis Genetic Analysis Consortium. Population variation of common cystic fibrosis mutations. Hum Mutat 1994;4:167-77.

5 The Cystic Fibrosis Genotype-Phenotype Consortium. Correlation between genotype and phenotype in patients Correlation between genotype and phenotype in patien

6 Welsh MJ, Smith AE. Molecular mechanisms of CFTR chloride channel dysfunction in cystic fibrosis. Cell 1993;73:1251-4.

7 Estivill X, Ortigosa I, Perez Frías J, et al. Clinical character istics of 16 cystic fibrosis patients with the missense mutation R334W, a pancreatic insufficiency mutation with var able age of onset and interfamilial clinical differences. Hum Genet 1995;95:331-6.

8 Chillon M, Casals T, Mercier B, et al. Mutations in the cystic fibrosis gene in patients with congenital absence of the vas deferens. N Engl f Med 1995;332:1475-80.
9 Gan K, Veeze HJ, Van den Ouweland AMW, et al. A cystic fibrosis mutation associated with mild lung disease. $N$ Engl f Med 1995;333:95-9.

10 Rozen R, Ferreira-Rajabi L, Robb L, Colman N. L206W mutation of the cystic fibrosis gene, relatively frequent in French Canadians, is associated with atypical presentations of cystic fibrosis. Am $\mathcal{F}$ Med Genet 1995;57:437-9.

11 Strong TV, Smit LS, Turpin SV, et al. Cystic fibrosis gene mutation in two sisters with mild disease and normal sweat electrolyte levels. N Engl f Med 1991;325:1630-4

12 Nunes V, Chillón M, Dörk T, Tümmler B, Casals T, Estivil $X$. A new missense mutation (E92K) in the firs transmembrane domain of the CFTR gene causes a benign cystic fibrosis phenotype. Hum Mol Genet 1993 1:79-80.

13 Chillón M, Casals T, Nunes V, Gimenez P, Pérez Ruiz E, Estivill $\mathrm{X}$. Identification of a new missense mutation (P205S) in the first transmembrane domain of the CFTR gene associated with a mild cystic fibrosis phenotype. Hum Mol Genet 1993;10:1741-2.

14 Dean $M$, White MB, Amos J, et al. Multiple mutations in highly conserved residues are found in mildly affected cystic fibrosis patients. Cell 1990;61:863-8.

15 Sheppard DN, Rich DP, Ostedgaard LS, Gregory RJ, Smith AE, Welsh MJ. Mutations in CFTR associated with mild disease form $\mathrm{Cl}$ - channels with altered pore properties. Nature 1993;362:160.

16 Highsmith WE, Burgh L, Zhou Z, et al. A novel mutation in the cystic fibrosis gene in patients with pulmonary disease but normal sweat chloride concentrations. $N$ Engl $f$ Med 1994;331:974-80.

17 Kanavakis E, Tzetis M, Antoniadi T, et al. Mild cystic fibrosis phenotype in patients with the $3272-26 \mathrm{~A}>\mathrm{G}$ mutation. f Med Genet 1995;32:406-7.

18 Anderson MP, Welsh MJ. Regulation by ATP and ADP of CFTR chloride channels that contain mutant nucleotidebinding domains. Science 1992;257:1701.

19 Zielenski J, Bozon D, Kerem B, Markiewicz D, Rommens JM, Tsui LC. Identification of mutations in exons 1 JM, Tsui LC. Identification of mutations in exons through 8 of the cystic fibrosis transmembrane conduct-

20 Goldberg DM, Durie PR. Biochemical tests in the diagnosis of chronic pancreatitis and in the evaluation of pancreatic insufficiency. Clin Biochem 1993;26:253-75.

21 National Committee for Clinical Laboratory Standards. Sweat testing: sample collection and quantitative analysis, approved guideline. NCCLS document C34-A, (ISBN 1-56238-260- 8). NCCLS, 771 East Lancaster Avenue, Villanova, Pennsylvania 19085, USA, 1994.

22 Fanen P, Ghanem N, Vidaud M, et al. Molecular characterization of cystic fibrosis: 16 novel mutations identified by analysis of the whole cystic fibrosis transmembran conductance regulator (CFTR) coding regions and splice site junctions. Genomics 1992;13:770-6.

23 Morral N, Dörk T, Llevadot R, et al. Haplotype analysis of 94 cystic fibrosis mutations with seven polymorphic CFTR DNA markers. Hum Mutat (in press)

24 Friedman KJ, Blalock ML, Silverman LM. Relatively high prevalence of the CFTR mutations G85E and 1154insTC. Hum Mutat 1995;6:95-6.

25 Bonizzato A, Bisceglia L, Marigo C, et al. Analysis of the complete coding region of the CFTR gene in a cohort of CF patients from north-eastern Italy: identification of $90 \%$ of the mutations. Hum Genet 1995;95:397-402.

26 Skach WR. CFTR mutants G85E and G91R insert charged residues into the first transmembrane segment and disrupt intracellular trafficking but do not alter transmembrane topology Pediatr Pulmonol 1995;suppl 12:191.

27 Chalkley G, Harris A. A cystic fibrosis patient who is homozygous for the G85E mutation has very mild disease. $\mathcal{J}$ Med Genet 1991;28:875-7.

28 Kerem E, Nissim M, Argaman Z, et al. Extremely high variability of clinical presentation among CF patients carryin the missense mutation G85E. Pediatr Pulmonol 1994, suppl 10:212. 